\title{
The need to introduce a Psychological Program into Emergency Medicine: early experiences in the field
}

\author{
Edgar Landa-Ramírez ${ }^{1,2 *}$ and Juan Luis Murillo-Cruz ${ }^{1,2}$ \\ ${ }^{1}$ Emergency Psychology Program, Department of Emergency Medicine, Hospital General “Dr. Manuel Gea González", Mexico City, Mexico; ${ }^{2}$ Health \\ Psychology and Behavioral Medicine Program, School of Psychology, Universidad Nacional Autónoma de Mexico, Mexico City, Mexico
}

\begin{abstract}
From the moment it was recognized as a medical specialty, emergency medicine has experienced an exponential growth in its clinical and research tasks, both nationally and internationally. Notwithstanding the sustained growth, some challenges are yet to be addressed in this field. The present article discusses the challenge of integrating psychology into the emergency medicine setting at research and clinical level. It introduces two main reasons that support the integration of psychology into medical emergencies: (1) conceptual consistency with the definition of health as set out by the World Health Organization, as well as with the biopsychosocial model. (2) The large body of empirical evidence related to the role of psychological problems present in patients, family members, and health staff within the emergency medicine department. Finally, the article provides a description of desirable characteristics that a psychological service of this kind should comprise, and it shares the experience of creating and integrating an exclusive emergency psychology service in a hospital setting.
\end{abstract}

Key words: Emergency psychology. Emergency medicine. Biopsychosocial model. Emergency department.

\section{La necesidad de introducir un Programa Psicológico en la Medicina de Emergencias: experiencias tempranas en el campo}

\section{Resumen}

Desde el momento en que la medicina de emergencia fue reconocida como una especialidad médica, ha experimentado un crecimiento exponencial en sus áreas clínicas y de investigación, tanto a nivel nacional como internacional. A pesar del crecimiento, todavía no se han abordado algunos desafíos en este campo. El presente artículo analiza el desafío de integrar a la psicología en el campo de la Medicina de Urgencias, a un nivel de investigación y práctica clínica. Existen dos razones principales que sustentan la integración de la psicología en el área de las urgencias médicas: (1) Consistencia conceptual con la definición de salud establecida por la Organización Mundial de la Salud, así como con el modelo biopsicosocial; (2) El gran cuerpo de evidencia empírica relacionada con el papel de los problemas psicológicos presentes en pacientes, familiares y personal de salud dentro del departamento de urgencias. Finalmente, el artículo proporciona una descripción

\section{Correspondence to:}

*Edgar Landa-Ramírez

Emergency Psychology Program,

Department of Emergency, Hospital General

"Dr. Manuel Gea González", Mexico City, Mexico

E-mail: edgar_landa_ramirez@yahoo.com.mx

Available online: 06-11-2019

Date of reception: 24-03-2019

Date of acceptance: 08-10-2019 DOI: 10.24875/REIE.19000025
Rev Educ Investig Emer. 2019;1(3):113-118 www.medicinadeemergencias.com

2604-6520 @ 2019 Sociedad Mexicana de Medicina de Emergencias, AC. Published by Permanyer México SA de CV. This is an open access article under the CC BY-NC-ND (http://creativecommons.org/licenses/by-nc-nd/4.0/). 
de las características deseables que un servicio psicológico de este tipo debería poseer, y además, comparte la experiencia de crear e integrar un servicio exclusivo de psicología de urgencias en un entorno hospitalario.

Palabras clave: Psicología de urgencias. Medicina de urgencias. Modelo biopsicosocial. Departamento de urgencias.

\section{Background}

From the moment it was recognized as a medical specialty - first in the United States ${ }^{1}$ and later internationally - emergency medicine has seen exponential and sustained growth in its clinical training ${ }^{2}$ and research programs $^{3}$, as well as in its impact on policy-makers. As a result, there are currently more than 4500 hospital-based emergency departments across the United States ${ }^{4}$, and there has been a proliferation of training programs in emergency medicine around the world, including Australia, Canada, Singapore, the United Kingdom, and Latin America. It is believed that close to 40,000 physicians practicing this discipline internationally graduated from one of these programs. Alliances have also been formed with the goal of building the workforce needed to produce the empirical evidence that will allow this field to grow ${ }^{3}$.

Notwithstanding the evident growth of this discipline, the critical need to continue advancing several areas and challenges of the emergency department globally has been acknowledged. For example: generating a larger number of rigorously designed studies; creating evidence-based guidelines that summarize the knowledge gained in the area; adequately translating the knowledge gained into clinical practice; and the structure of the organization $^{5,6}$. It is the view of the authors that one of the most significant gaps that still exist and which is yet to receive the attention it deserves in the field of emergen$\mathrm{cy}$, is the lack of recognition and integration of the psychosocial dimension into emergency medicine in the hospital setting. Therefore, there is a prevailing need to produce specialists in the area who are immersed in daily clinical research and practice in this field. There are at least two main reasons why the psychological dimension should be considered, evaluated, and integrated into in-hospital emergency medicine: (1) consistency with the conceptual dimension of the definition of health; and (2) the growing empirical evidence that highlights the relevant role that psychosocial factors play in patients treated in the emergency medicine department.

\section{Conceptual justification}

The World Health Organization declared that "Health is a state of complete physical, mental and social well-being and not merely the absence of disease or infirmity"7,8. In 1977, Engel described the need to build a model in the health sector consistent with the above definition, which would avoid excluding and reducing the "biomedical" model to merely biological factors, and instead would accommodate the psychological, behavioral, and social factors ${ }^{9}$. However, in the case of emergency medicine, neither the integration nor the recognition of the psychological dimension seems to be clear. A good example is the definition of emergency medicine provided by the American College of Emergency Physicians: "Emergency medicine is the medical specialty dedicated to the diagnosis and treatment of unforeseen illness or injury... The practice of emergency medicine includes the initial evaluation, diagnosis, treatment, coordination of care among multiple providers, and disposition of any patient requiring expeditious medical, surgical, or psychiatric care"10.

Both, the World Health Organization ${ }^{11}$ and the The International Federation for Emergency Medicine ${ }^{12}$ state that emergency medicine is dedicated to the prevention, diagnosis, and treatment of acute and urgent of illness or injury affecting people but none of this two organizations has considered the psychological factors as a part of the daily tasks in the emergency medicine. The psychological dimension is a sine qua noncondition of the human being, and its separation from the organic aspect is only valid due to philosophical considerations derived from Cartesian dualism ${ }^{9}$, rather than practical concerns. Thus, leaving such dimension out of the patient's care would entail a serious omission of an indivisible part of the patient treated in emergencies. Something similar happens with the social, idiosyncratic, and cultural dimensions of the patient, which is why recently a recommendation was issued to consider the cultural background of the patients as an essential element of their care during their stay in the emergency medicine department ${ }^{13}$. Undoubtedly, a similar recommendation should be made to integrate the psychological aspect of emergency medicine.

\section{Empirical justification}

Over the past few decades, there have been several studies whose empirical data underscore the relevance 
of the psychological factors in caring for the patient, the informal caregiver (normally a relative), or the formal caregiver (health staff) within emergency services. Such is the case that patients treated in the emergency medicine department have been found to have a high likelihood of perceiving the situation as very stressful, and this can be further associated with moods such as sadness, hopelessness, anxiety, depression, and frustration ${ }^{14}$. Studies report that around $40 \%$ of patients show some kind of psychological distress and they even describe that up to $12 \%$ of overall consultations in emergency medicine are related to mental health problems and substance abuse, where "mood disorder, anxiety disorders, alcohol-related conditions, drug-related conditions, schizophrenia/psychoses, and intentional self-harm" are the most common reasons for visiting the emergency department ${ }^{14,15}$.

As for the patient's informal caregivers, some studies suggest that they are also on a state of tension and emotional vulnerability, making it likely that they experience physical and mental health problems, a reduced quality of life, and develop negative emotions such as anger, depression, anxiety, distress, overload informal caregiver burden, loss of employment, and financial problems $^{16,17}$; and in very specific cases, like being notified of their patient's death, there can be exacerbated emotional responses such as aggressive behaviors, shock, and emotional crisis $^{18}$. In addition to being emotional responses that deserve treatment on their own right, the above will impact the way patients and their relatives make use of emergency services, making them more likely to have an early unplanned rehospitalization ${ }^{16}$. Health staff in the context of emergency medicine is exposed to developing a large number of situations where the psychological dimension is of considerable importance. Studies report that they may develop burnout, depression, anxiety, hopelessness, and suicide attempt, all of which have an impact on the physical health, work/personal dissatisfaction, quality of interaction among colleagues in the emergency medicine department, as well as on the quality of the service offered and the potential mistakes they make in the area $^{19-21}$. Further information is provided in table 1.

The above information emphasizes the need to address the psychological dimension of patients, informal caregivers, and health staff in the emergency medicine department. To do so, we can follow the recommendations provided by the Canadian Association of Emergency Physicians. A first necessary step is to build a broader body of knowledge, derived from robust studies which allow to create clinical guidelines in the field
Table 1. Common psychological problems in the emergency department

\begin{tabular}{|l|l|}
\hline Population & Psychological problems \\
\hline Patients & $\begin{array}{l}\text { Anxiety } \\
\text { Depression } \\
\text { Substance abuse } \\
\text { Intentional self-harm } \\
\text { Sadness } \\
\text { Hopelessness } \\
\text { Suicide attempts }\end{array}$ \\
\hline Informal caregivers & $\begin{array}{l}\text { Caregiver burden } \\
\text { Aggressive behaviors } \\
\text { Emotional crisis } \\
\text { Anxiety } \\
\text { Depression }\end{array}$ \\
\hline Anger \\
\hline Health staff & Burnout \\
\hline Hopelessness \\
\hline Depression \\
\hline Anxiety \\
Work disappointment \\
\hline
\end{tabular}

so that the emergency team can subsequently get involved in the process of change, and adapted to context-specific conditions, while also measuring the impact of these changes and interventions ${ }^{5}$.

\section{Psychological approach}

It is the opinion of the authors that an evidence-based psychology 22 must be inserted and should be considered essential when creating a branch of psychology specialized exclusively in emergency medicine (something similar has already been done with the oncological field of psycho-oncology) where, in addition to psychological topics, psychologists can study the medical concepts necessary to understand the relevant elements of the diagnostics, prognosis, and procedures in emergency medicine. This will make the psychologist become aware of the needs and dynamics of the patients, informal caregivers and health staff in the emergency medicine department.

Three essential pillars can be developed to support this budding discipline: research, teaching, and interdisciplinary professional clinical practice. In terms of research, the goal should be to adapt it to international recommendations, which require to file records in an appropriate database before initializing the studies, while paying special attention to the ethical concerns, the conditions specific to the hospital setting, and measuring both the intervention processes and the results in clinical variables ${ }^{5}$. 
As for teaching, it would be advantageous to combine the clinical, theoretical, and methodological courses taught at the hospital for both psychologists and health staff in the department, with a "journal club" of select topics, accompanied by "bedside teaching," which has been identified as an important teaching method in the emergency medicine field whenever it is provided alongside positive feedback ${ }^{23}$. When it comes to emotional crisis intervention related to death notification, it has become especially relevant to use role-playing games in which peers, experienced people, relatives, or professional actors participate, to foster the development of skills that allow for the containment of a patient going through an emotional $\mathrm{crisis}^{18}$.

To develop an adequate professional clinical practice, the profile that must be found is a professional psychologist or behavioral expert (e.g., in behavioral medicine) with interviewing strategies, such as empathy and active listening, with the purpose to identify the main needs of the patients, informal caregivers, and health staff within the hospital. Similarly, these skills should allow them to make therapeutic decisions and generate brief interventions based on the clinical guidelines and recommendations in place for the conditions being treated while evidence is generated to address these problems in the specific context of emergency medicine. Another relevant point is to ensure that professional psychologist is able to conduct interdisciplinary with the health staff in the emergency department due to the special needs of emergency medicine; particularly, to intervene during behavioral emergencies or emotional crises that occur in family members, especially when they are notified of a diagnosis, a negative prognosis or sudden death ${ }^{24-26}$. One last recommendation is that they have the profile of a person able to adapt to the defiant conditions of this service, both in their interactions and physical condition.

\section{The Mexican experiences}

With the intention of addressing the psychological needs of the emergency department, a 1-year specialized Program in Emergency Psychology was created in 2015 at the "Hospital General Dr. Manuel Gea González" in Mexico City. This program now trains psychologists in this field and helps them develop the skills described before. Given the context of Mexico as a developing country, the path has not been easy. Yet, implementing change has been possible with the help of the hospital and two of the main higher education institutions in Mexico: The National Autonomous University of Mexico
(UNAM) and the National Polytechnic Institute (IPN). Both institutions have supported this task through clinical, methodological, and statistical consultancies with staff specialized in psychological and health research, behavioral medicine, and biomedical research.

Specifically, a collaboration program was established with UNAM through the School of Psychology, at the undergraduate and postgraduate levels. Undergraduate students are invited to enroll and collaborate in research projects and provide support in applied interventions. Their main task is to assess patients and informal caregivers to identify psychological needs to address. At postgraduate level, doctoral and master students are welcome to support and develop research projects and apply evidence-based interventions such as problem-solving therapy, relaxation training, and techniques for cognitive restructuring.

The process of psychological attention in the emergency department starts with an assessment performed by undergraduate students. If a patient or an informal caregiver has an emotional or behavioral problem, a master or a doctoral student is informed by the assessor and both, undergraduate and postgraduate student, develop, and apply an intervention plan. This plan could be a brief intervention (e.g., usually for emotional crisis intervention related to the death of a loved one) or a longterm intervention (e.g., Evidenced-based psychotherapy for anxiety, depression, adherences, and grief). The candidates for the initial assessment are those patients who are clinically stable, and there is no cognitive impairment that could affect the results. In case of the relatives, the assessment is done to the informal caregiver, the person who is in charge of the patient. A summary of the clinical psychological process is provided in figure 1 .

The psychological support to health staff is offered when the authorities identify and refer to treatment to a medical resident, medical employee, or a nurse. In these cases, the master and doctoral degree is a requirement to attend health staff.

Finally, in the case of teaching, several experts in a diversity of fields (philosophical, theoretical, clinical, methodological, and statistical) have been invited to teach courses. On the other hand, every day, graduate students attend the medical courses taught to emergency residents and, occasionally, they are also invited to teach the psychological aspects of the field and to give complementary training.

Throughout the 4 years, the program has been in place, the main activities that have opened the door of the emergency department to psychologist in Mexico have been those focused on evaluating and treating 


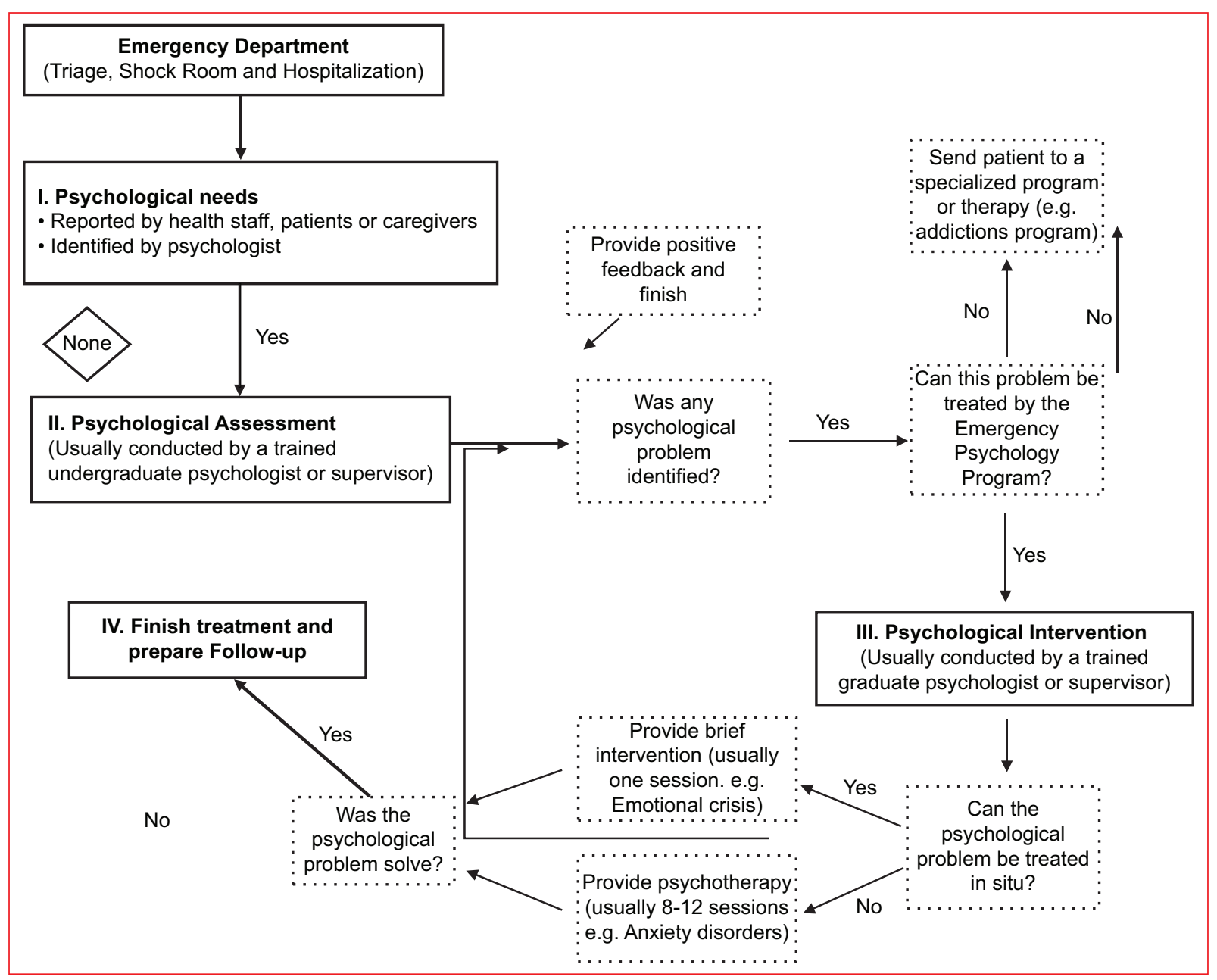

Figure 1. A summary of the clinical psychological process into the emergency department.

anxiety, depression, burnout, and psychosocial problems in the residents working in emergency department. In the case of family members, the program has encouraged interdisciplinary work to provide emotional support and crisis intervention for relatives whose patient has passed away. Moreover, in the case of patients, the work has been focused on identifying and intervening in problems such as anxiety, stress, depression, substance consumption, and suicide attempt both during hospitalization and in the triage area. It is also important to point that the work done in the emergency department is not exclusive about emotional issues, some interventions have aimed to solve patient's concerns related to the medical condition or to modify the behaviors that negatively affect the patient's health to develop the necessary skills to cope with the illness effectively.

Further, due to the experience handling emotional crises during the earthquake that hit Mexico City on September 19, 2017, the Emergency Psychology
Program, with prior approval of the Federal Government through the National Center for Prevention of Disasters, created out-of-hospital brigades focused on providing emotional support and crisis intervention to victims located in various devastated areas across the city.

Despite the advancements, there are several challenges ahead that will have to be overcome if we are to successfully introduce psychology into emergency medicine. A major one is the health sector's economic barriers, which prevents them from assigning a larger number of hired psychologists to address the needs of the area. In our experience, this problem can be tackled through the "goodwill" of the hospital management and the supervised support of undergraduate and graduate students from several universities. Something similar happened when the specialization in emergencies first opened decades ago ${ }^{1}$. Another important point will be to work toward gaining official national and international 
recognition for the field of emergency psychology. This official recognition will bring greater interest from the different populations within and outside the health sector.

Likewise, a critical challenge is to evaluate in clear and robust terms the effects of inserting psychology in the emergency medicine department, both at the organizational and individual levels. Maybe as same as other studies in palliative care field ${ }^{27}$ this aim can be achieved comparing the psychological care integrated with standard emergency care versus only standard emergency care on outcomes such as quality of life, patient's satisfaction, admissions and readmission, and costs in emergency room ${ }^{28}$. This point will help to generate data which makes it possible to take decisions that result in changes and adjustments in the approach to patients, informal caregiver and health staff is approached in the emergency medicine.

Finally, it is important to create an adequate transition toward interdisciplinary work for the emergency department's health staff. In our experience, it has been useful to openly discuss the evidence and international recommendations in the field, in addition to seeking agreements with workgroups to make changes, and finding key people who make those changes possible. The above will help to form generations of health staff who are increasingly less reluctant to change.

\section{Conclusions}

This article is an initial effort to describe the importance of recognizing the psychological needs in emergency medicine, as well as the necessity to develop and integrate the branch of emergency psychology to address the main day-to-day psychological demands of in-hospital emergency medicine. Even though the path is long, the hope is that this description may at least be the initial spark that helps to address these great needs on a national and global scale, this way fostering a better interdisciplinary approach to the treatment of medical emergencies to improve the quality of care delivered in this service.

\section{Conflicts of interest and funding}

The authors declare there are no conflicts of interest to disclose. This article received no funding from any institution.

\section{References}

1. Suter RE. Emergency medicine in the United States: a systemic review. World J Emerg Med. 2012;3:5-10.

2. Hobgood C, Mulligan T, Bodiwala G, Cameron P, Holliman JJ, Kwan J, et al. International federation for emergency medicine model curriculum for continuing professional development. CJEM. 2015;17:295-309.

3. Abar B, DeRienzo V, Glick J, Wood N, Shah MN, Schneider S, et al. Implementation of an emergency medicine research associates program: sharing 20 years of experience. West J Emerg Med. 2018;19:606-12.

4. Hsia RY, Kellermann AL, Shen YC. Factors associated with closures of emergency departments in the United States. JAMA. 2011;305:1978-85.

5. de Wit K, Curran J, Thoma B, Dowling S, Lang E, Kuljic N, et al. Review of implementation strategies to change healthcare provider behaviour in the emergency department. CJEM. 2018;20:453-60.

6. Tavender EJ, Bosch M, Fiander M, Knott JC, Gruen RL, O'Connor D, et al. Implementation research in emergency medicine: a systematic scoping review. Emerg Med J. 2016;33:652-9.

7. World Health Organization. Constitution of the World Health Organization. Geneva: World Health Organization; 1948.

8. International Conference on Primary Health Care. Declaration of alma-ata. WHO Chron. 1978;32:428-30.

9. Engel GL. The need for a new medical model: a challenge for biomedicine. Science. 1977;196:129-36.

10. American College of Emergency Physicians. Definition of emergency medicine. Ann Emerg Med. 2016;68:142-3.

11. World Health Organization. Emergency and Trauma Care. Emergency Care Systems. Available from: http://www.who.int/emergencycare/systems/en.

12. The International Federation for Emergency Medicine. About us. IFEM Definition of Emergency Medicine. Available from: https://www.ifem.cc/about-us.

13. American College of Emergency Physicians. Cultural awareness and emergency care. Ann Emerg Med. 2008;52:189.

14. Faessler L, Kutz A, Haubitz S, Mueller B, Perrig-Chiello P, Schuetz P, et al. Psychological distress in medical patients 30 days following an emergency department admission: results from a prospective, observational study. BMC Emerg Med. 2016;16:33.

15. Agency for Healthcare Research and Quality. Mental Health and Substance Abuse-related Emergency Department Visits among Adults, 2007: HCUP Statistical Brief \#92. Rockville: Agency for Healthcare Research and Quality; 2010.

16. Bonin-Guillaume S, Durand AC, Yahi F, Curiel-Berruyer M, Lacroix O, Cretel $\mathrm{E}$, et al. Predictive factors for early unplanned rehospitalization of older adults after an ED visit: role of the caregiver burden. Aging Clin Exp Res. 2015;27:883-91.

17. Sewitch MJ, Yaffe MJ, McCusker J, Ciampi A. Helping family doctors detect vulnerable caregivers after an emergency department visit for an elderly relative: results of a longitudinal study. BMC Fam Pract. 2006;7:46.

18. Shoenberger JM, Yeghiazarian S, Rios C, Henderson SO. Death notification in the emergency department: survivors and physicians. West $J$ Emerg Med. 2013;14:181-5.

19. Arora M, Asha S, Chinnappa J, Diwan AD. Review article: burnout in emergency medicine physicians. Emerg Med Australas. 2013;25:491-5.

20. Shanafelt TD, Boone S, Tan L, Dyrbye LN, Sotile W, Satele D, et al. Burnout and satisfaction with work-life balance among US physicians relative to the general US population. Arch Intern Med. 2012;172:1377-85.

21. West CP, Tan AD, Habermann TM, Sloan JA, Shanafelt TD. Association of resident fatigue and distress with perceived medical errors. JAMA. 2009;302:1294-300.

22. Report of the 2005 Presidential Task Force on Evidence-Based Practice. American Psychological Association; 2005. Available from: http://www. apa.org/practice/resources/evidence/evidence-based-report.pdf.

23. McNeil C, Muck A, McHugh P, Bebarta V, Adams B. Bedside rounds versus board rounds in an emergency department. Clin Teach. 2015;12:94-8.

24. Wong $A H$, Wing $L$, Weiss $B$, Gang M. Coordinating a team response to behavioral emergencies in the emergency department: a simulation-enhanced interprofessional curriculum. West J Emerg Med. 2015;16:859-65.

25. Hobgood C, Harward D, Newton K, Davis W. The educational intervention "GRIEV_ING" improves the death notification skills of residents. Acad Emerg Med. 2005;12:296-301.

26. Cunha S, Soares-Oliveira M, Pereira N. Early psychological intervention in prehospital emergency care systems. J Emerg Med. 2009;36:404-6.

27. Temel JS, Greer JA, Muzikansky A, Gallagher ER, Admane S, Jackson VA, et al. Early palliative care for patients with metastatic non-small-cell lung cancer. N Engl J Med. 2010;363:733-42.

28. Sabbatini AK, Kocher KE, Basu A, Hsia RY. In-hospital outcomes and costs among patients hospitalized during a return visit to the emergency department. JAMA. 2016;315:663-71. 